\title{
Gerenciamento de Resíduos dos Laboratórios da Área de Saúde do Campus da Universidade Severino Sombra, Vassouras - RJ
}

\author{
José Carlos do Nascimento \\ Universidade Severino Sombra, CCS \\ zecarlos.nascimento@hotmail.com \\ Rosana Canuto Gomes \\ Universidade Severino Sombra, CCS/CECETEN \\ rosanacanutogomes@gmail.com \\ Carlos Eduardo Cardoso \\ Universidade Severino Sombra, CECETEN \\ cardoso221@yahoo.com \\ Luzia Teixeira de Azevedo Soares Semêdo \\ Universidade Severino Sombra, CCS/CECETEN \\ luziasemedo@gmail.com
}

\begin{abstract}
Resumo: Os residuos gerados pelas atividades humanas representam um dos maiores problemas da atualidade, uma vez que tratados de maneira negligente e inadequada constituem graves riscos ao meio ambiente, à saúde humana e de animais. Integrado a este universo, temos a questão dos resíduos de serviços de saúde (RSS), que por suas particularidades torna-se inexeqüível o seu lançamento em rede pública de esgotos ou em corpos d'água, exigindo-se para isso, soluções técnicas e economicamente viáveis em face à melhor tecnologia disponível (ANVISA 2005). A consciência ambiental da população e a legislação tem levado as instituições hospitalares, de ensino e pesquisa a implantarem a gestão de resíduos laboratoriais buscando, desta forma, minimizar os riscos e impactos causados por tais resíduos. O presente trabalho tem por objetivo identificar e descrever a quantidade diária dos resíduos gerados nos laboratórios da área de saúde do Campus da Universidade Severino Sombra, justificandose pela imprescindivel necessidade de adequação às normas estabelecidas por lei e aos protocolos da instituição reconhecendo que muito já foi feito, todavia, ainda há muito o que aprimorar.
\end{abstract}

Palavras-chave: Resíduos de serviços de saúde. Atividade de laboratório. Gerenciamento de resíduos. 


\title{
Waste Management Area of the Laboratories of the Health Campus Severino Sombra University, Vassouras - RJ
}

\begin{abstract}
The waste generated by human activities represent one of the biggest problems today, as treated constitute gross negligence and inadequate risk to the environment, human health and animals. Integrated in this universe, there is the issue of waste of health services (RSS), which for its particularities make its launch be unenforceable in public sewage system or water bodies. All this idea demands technical solutions and economically viable means, given the best available technology (ANVISA 2005). The population's environmental awareness and legislation has led hospitals, teaching and research to implement the waste management laboratory seeking, minimizing, thus, the risks and impacts caused by such waste. This work aims to identify and describe the daily amount of waste generated in laboratories within the health area of Severino Sombra University Campus. The existence of such study is justified by the imperative need to fit in with the norms established by law and the institution's protocols, recognizing that, though much has already been done, there is still a lot to improve.
\end{abstract}

Keywords: Waste of health services. Laboratory activities. Waste management.

\section{Introdução}

\section{Resíduos Sólidos}

A concentração demográfica e o aumento do consumo de bens geram uma enorme quantidade de resíduos de todo tipo, procedentes tanto das residências como das atividades públicas e dos processos industriais. Todos esses materiais recebem denominação de lixo e sua eliminação, e possível reaproveitamento, são desafios a serem vencidos pelas sociedades modernas (Silva e Soares, 2004).

Segundo a ANVISA (2006), o termo lixo é usualmente utilizado para designar tudo aquilo que não tem mais utilidade, enquanto resíduo é mais utilizado para designar sobra (refugo) do beneficiamento de produtos.

De acordo com o Instituto de Pesquisa Técnica/Compromisso Empresarial para Reciclagem (IPT/Cempre) (2000), os resíduos sólidos podem ser classificados de várias formas: 1) por sua natureza física: seco ou molhado; 2) por sua composição química: matéria orgânica e matéria inorgânica; 3 ) pelos riscos potenciais ao ambiente; e 4) quanto à origem.

No entanto, as normas e resoluções existentes classificam os resíduos sólidos em função dos riscos potenciais ao ambiente e à saúde, como também, em função da natureza e origem. 
A Resolução n. ${ }^{\circ}$ 05/93 do CONAMA, conceitua resíduos sólidos baseando-se na definição dada pela NBR 10.004/87 da ABNT, que revela:

\begin{abstract}
Resíduos nos estados sólidos e semi-sólidos, que resultam de atividades da comunidade de origem: industrial, doméstica, hospitalar, comercial, agrícola, de serviços e de varrição. Ficam incluídos nesta definição os lodos provenientes de sistemas de tratamento de água, aqueles gerados em equipamentos e instalações de controle de poluição, bem como determinados líquidos cujas particularidades tornem inviável seu lançamento na rede pública de esgotos ou corpos d'água, ou exijam para isso soluções técnicas e economicamente inviáveis, em face à melhor tecnologia disponível (Takada, 2003).
\end{abstract}

\title{
Resíduos de Serviços de Saúde e a Questão Ambiental
}

Com o início da assistência hospitalar, certamente houve o início da geração de resíduos de serviços de saúde, entretanto, somente a pouco mais de uma década estes vêm se tornando um assunto bastante discutido, devido ao grande desenvolvimento ocorrido no campo da infecção hospitalar e do meio ambiente (Ribeiro Filho 2000).

Os resíduos dos serviços de Saúde são geralmente associados a "lixo hospitalar" ou resíduos sólidos, de forma genérica, embora possuam características dos resíduos sólidos em geral, também possuem a especificidade da atividade de saúde em que é produzido, o que determina o risco ao ambiente, à saúde humana e de animais, principalmente se forem tratados de forma negligente e sem o devido controle (Anvisa, 2006).

Dados da Associação Brasileira de Empresas de Limpeza Pública e Resíduos Especiais (ABRELPE) mostram que o Brasil, infelizmente, está longe de solucionar definitivamente a questão dos Resíduos de Serviços de Saúde (RSS), pois se trata de algo atrelado à problemática dos resíduos como um todo (Anvisa, 2006).

Os Resíduos de serviços de saúde representam em torno de $1 \%$ a 3\% da quantidade total dos resíduos gerados no país e têm um papel importante no cenário da saúde pública (Anvisa, 2006).

De acordo com Garcia e Ramos (2004), é importante salientar que, diferentemente dos resíduos domiciliares comuns, os de serviços de saúde podem apresentar grande quantidade de substâncias químicas - como desinfetantes, antibióticos e outros medicamentos decorrendo daí também o risco químico além do biológico. Além disso, a disposição conjunta dos resíduos contendo micro-organismos e substâncias químicas pode provocar um aumento das populações bacterianas resistentes a certos antibióticos, detectadas no esgoto de hospitais. Dessa forma, o mau gerenciamento dos resíduos de serviços de saúde pode favorecer a propagação da resistência bacteriana múltipla aos antimicrobianos (Garcia e Ramos, 2004).

A destinação inadequada dos resíduos sólidos põe em risco o meio ambiente e está envolvida na determinação da emergência e re-emergência de doenças infecciosas. Sendo assim, o tratamento adequado dos resíduos de serviços de saúde, especialmente aqueles 
contendo material biológico de pacientes acometidos por doenças novas ou emergentes - de patogênese ainda pouco conhecida, é de fundamental importância para a contenção da propagação dessas doenças, principalmente daquelas decorrentes do meio ambiente contaminado (Garcia e Ramos, 2004).

Segundo a Anvisa (2006), o risco para o Meio Ambiente é a probabilidade da ocorrência de efeitos adversos ao meio ambiente, decorrentes da ação de agentes físicos, químicos ou biológicos, causadores de condições ambientais potencialmente perigosas que favoreçam a persistência, disseminação e modificação desses agentes no ambiente.

Conhecendo-se os riscos oriundos dos resíduos de serviços de saúde é fundamental que se busquem soluções para a problemática, que se pense na introdução de uma nova cultura direcionada ao tratamento de resíduos, que tenha por objetivo promover o bem estar do profissional de saúde e da comunidade em geral. Para este fim, estabeleceu-se o Gerenciamento de Resíduos de Serviços de saúde (GRSS).

Entende-se como Gerenciamento de Resíduos de Serviços de Saúde o conjunto de procedimentos de gestão, planejados e implementados a partir de bases científicas e técnicas, normativas e legais, com o objetivo de minimizar a produção de resíduos e proporcionar aos resíduos gerados um encaminhamento seguro, de forma eficiente, visando à proteção dos trabalhadores, à preservação da saúde pública, dos recursos naturais e do meio ambiente (Brasil, 2003).

O Gerenciamento de Resíduos de Saúde representa um passo para uma melhor qualidade de vida, todavia, cabe salientar que a problemática se torna visível no fato de que grandes geradores de resíduos de serviços de saúde possuem maior consciência a respeito do planejamento adequado e necessário para gerenciá-lo; contudo, os pequenos geradores muitas vezes não possuem essa consciência e os conhecimentos necessários. Muitas vezes também lhes falta infraestrutura para realizar adequadamente o gerenciamento dos resíduos de serviços de saúde. Além disso, parte dos resíduos domiciliares possui características que fazem com que se assemelhem aos resíduos de serviços de saúde. Por exemplo, pacientes diabéticos - que administram insulina injetável diariamente e usuários de drogas injetáveis, geram resíduos perfurocortantes, que geralmente são dispostos juntamente com os resíduos domiciliares comuns (Garcia e Ramos, 2004).

\section{Classificação dos Resíduos de Serviços de Saúde}

A classificação dos resíduos de serviços de saúde, estabelecida na Resolução CONAMA n. ${ }^{\circ}$ 05/93, com base na composição e características biológicas, físicas e químicas, tem como finalidade propiciar o adequado gerenciamento desses resíduos, no âmbito interno e externo dos estabelecimentos de saúde (Takada, 2003).

Segundo o Manual de Gerenciamento de Resíduos de Serviços de Saúde, (2004) elaborado pela Secretaria de Saúde de Goiás, a classificação dos Resíduos de Serviços de Saúde objetiva destacar a composição dos resíduos segundo as suas características biológicas, físicas, químicas, estado da matéria e origem, para o seu manejo seguro.

De acordo com a Resolução da Diretoria Colegiada (RDC) ANVISA n. ${ }^{0}$ 306/04 e Resolução CONAMA n. ${ }^{\circ}$ 358/05, que em harmonia estabelecem e definem a classificação, 
as competências e responsabilidades, as regras e procedimentos para o gerenciamento dos Resíduos de Serviços de Saúde, desde a geração até a disposição final.

Estes órgãos convencionam que os resíduos de serviços de saúde são classificados em cinco grupos: A, B, C, D e E, o que fundamentou o presente trabalho.

\section{Recipientes coletores de resíduos de serviços de saúde}

Os recipientes coletores devem ter alta vedação, ser confeccionados de material estável e, em alguns casos, serem combustíveis. Deve-se expô-los em local ventilado, principalmente, quando contiverem solventes.

De acordo com as normas técnicas, os coletores devem permitir o reconhecimento dos resíduos contidos nos sacos e recipientes, fornecendo informações ao correto manejo dos resíduos (Anvisa, 2010).

Os recipientes de coleta interna e externa, assim como os locais de armazenamento onde são colocados os resíduos de serviços de saúde, devem ser identificados em local de fácil visualização, de forma indelével, utilizando símbolos, cores e frases, além de outras exigências relacionadas à identificação de conteúdo e aos riscos específicos de cada grupo de resíduos de acordo com NBR 7500.

\section{Legislação}

Para fins de atendimento à elaboração do Plano de Gerenciamento de Resíduos Sólidos Sépticos e/ou Resíduos de serviços de saúde existe, no Brasil, uma coleção de leis (Federal: n. ${ }^{\circ}$ 9605/98, Estadual: n. ${ }^{\circ}$ 4191/2003 e Municipal - Lei Orgânica do Município de Vassouras n. ${ }^{\circ}$ 1.450/90 [Brasil 2008, Monteiro 2001], decretos, resoluções (CONAMA n. ${ }^{\circ} 01 / 86 ;$ n. ${ }^{\circ} 05 / 88 ;$ n. ${ }^{o} 006 / 91 ;$ n. ${ }^{o} 008 / 91 ;$ n. ${ }^{\circ} 05 / 93 ;$ n. ${ }^{\circ} 275 / 01 ;$ n. ${ }^{\circ} 283 / 01$ e ANVISA RDC 33/03[ANVISA 2003] e normas (NBR 7.500/87; NBR 10.004/87; NBR 12.235/92; NBR 12.807/93; NBR 12.808/93; NBR 12.809/93; NBR 12.810/93; NBR 9.190/93; NBR 9.191/93; NBR 9.195/93; NBR 13.055/93; NBR 13.056/93 NBR 12.890/93; NBR 11.175/90; NBR 13.853/97; CNEN - NE 6.05/98) [Brasil 2008].

\section{Segurança Ocupacional}

Segundo a ANVISA (2006), o risco à saúde é a probabilidade da ocorrência de efeitos adversos à saúde, relacionados com a exposição humana a agentes físicos, químicos ou biológicos em que um indivíduo exposto a um determinado agente apresente doença, agravo ou até morte, dentro de um período determinado de tempo ou idade, e o profissional da área da saúde expõe-se continuamente a estes agentes de risco.

O risco ocupacional para os trabalhadores da saúde é um assunto muito discutido nas últimas décadas. Entretanto, os registros dos acidentes ocorridos nas unidades de saúde não retratam a real situação, para assegurar a integridade dos trabalhadores dessa área, estabeleceu-se normas técnicas que visam protegê-los (Jusbrasil, 2011).

As instituições geradoras de resíduos de serviços de saúde devem manter um Plano 
de Gerenciamento de Resíduos de Saúde (PGRSS), neste, deve-se incluir o Programa de Capacitação de Pessoal para o Manejo de resíduos de serviços de saúde. O pessoal envolvido diretamente com o Plano de Gerenciamento de Resíduos de Serviços de Saúde deve ser capacitado na ocasião de sua admissão e mantido sob treinamento periódico para as atividades de manejo de resíduos, incluindo a sua responsabilidade com higiene pessoal e dos materiais. A capacitação deve abordar a importância da utilização correta de equipamentos de proteção individual, bem como a necessidade de mantê-los em perfeita higiene e estado de conservação. Todos os profissionais que trabalham no estabelecimento, mesmo os que atuam temporariamente ou não estejam diretamente envolvidos nas atividades do Plano de Gerenciamento de Resíduos de Serviços de Saúde - PGRSS, devem conhecer o sistema adotado para o gerenciamento de resíduos de serviços de saúde, a prática de segregação de resíduos, reconhecimento de símbolos, expressões, padrões de cores adotados, localização de abrigos de resíduos, entre outros fatores indispensáveis à completa integração ao Plano.

As medidas de higiene e segurança permitem que o pessoal envolvido no PGRSS, além de proteger sua própria saúde, possa desenvolver, com maior eficiência, seu trabalho, conhecer o cronograma de trabalho, sua natureza e responsabilidade, assim como o risco a que estará exposto.

Acredita-se que o gerenciamento adequado dos resíduos possa contribuir significativamente para a redução da ocorrência de acidentes de trabalho, especialmente aqueles provocados por perfurocortantes. Dessa forma, também poderia ser reduzida a exposição percutânea dos trabalhadores dos serviços de saúde a materiais biológicos, uma medida no contexto da biossegurança que teria grande valor para a saúde ocupacional (Garcia e Ramos 2004).

Sabendo que a gestão de resíduos de saúde implica também conscientização referente ao ambiente, já que trata igualmente do destino adequado dos resíduos produzidos em laboratório, a implantação de um programa de gestão de resíduos de serviços de saúde no campus Vassouras, da Universidade Severino Sombra não visa apenas à administração dos resíduos produzidos, vai além, engloba ações que possibilitam a preservação do ambiente, bem como a diminuição de risco de contaminação, por estes resíduos, desprezados negligentemente.

As principais estratégias para a diminuição de riscos ambientais e de segurança em laboratórios baseiam-se nas seguintes medidas: Minimizar o estoque de produtos químicos, deste modo reduzem-se também as necessidades de espaço requerido e de eventuais perdas financeiras devido à perda de validade dos produtos; substituir produtos tóxicos por produtos com menor grau de toxicidade ou inócuos; aplicar o conceito da microescala, ou seja, reduzir a escala das experiências e protocolos a menor possível que permita atingir as necessidades de formação envolvidas; reduzir ao essencial o número de ensaios (incluindo o número de amostras e número de réplicas); promover a separação dos resíduos, maximizando as possibilidades de recuperação de materiais mediante sua reutilização e reciclagem; Promover informações sobre os benefícios ambientais e de segurança decorrentes dos esforços desenvolvidos para a diminuição de riscos; garantir que todos os produtos armazenados, incluindo resíduos que se encontram adequadamente rotulados, e que as fichas de dados de segurança estejam disponíveis. A Resolução 
Ministerial N..$^{\circ} 358$, de 29 de abril de 2005, diz respeito ao tratamento e a disposição final dos resíduos dos serviços de saúde, dando também outras providências.

\section{Materiais e Métodos}

\section{Coleta dos Resíduos de Serviços de Saúde nos Laboratórios do Campus Vassouras, da Universidade Severino Sombra}

A coleta foi realizada nos sete laboratórios de saúde existentes no campus Vassouras da Universidade Severino Sombra durante 107 (cento e sete) dias. Neles foram coletados resíduos infectantes, perfurocortantes, químicos, comuns e biológicos, inexistindo, no entanto, resíduos radioativos.

\section{Resíduos Presentes nos Laboratórios}

Segundo o MANUAL DE GERENCIAMENTO DE RESÍDUOS DE SERVIÇOS DE SAÚDE (2004), atualmente, são classificados 5 (cinco) tipos de resíduos em serviços de saúde: resíduos químicos, biológicos, radioativos, físicos e perfurocortantes os quais podem ser sólidos ou líquidos, o que exige maior atenção e cuidados com o manejo e o descarte.

O campus Vassouras, da Universidade Severino Sombra dispõe de sete laboratórios que são usados por discentes e docentes dos cursos da área de saúde, sendo, portanto, verdadeiros geradores de resíduos de serviços de saúde a saber:

Fisiologia: carcaças de animais, barbantes (sujos de sangue), papel branco, papel-toalha, luvas, algodão, lancetas, papel-alumínio, bisturi, agulhas, seringas, frasco de álcool e frasco de hipoclorídrico;

Microbiologia/Parasitologia: urina, fezes, lamínulas, papel-toalha, algodão, gaze, placas descartáveis com meios de cultura (autoclavados), bactérias e fungos (autoclavados) meios de cultura, papel-alumínio, papel branco, papel-filtro, papel pardo (embalagens com fitas de autoclave e fitas comuns), luvas, água da autoclave, swab, alças descartáveis, fósforo, frasco de álcool e frasco de hipoclorídrico;

Histologia/Embriologia: Lâminas quebradas, papel branco, frasco de álcool e frasco de hipocloridrico;

Farmacologia: algodão, papel-toalha, papel branco, agulhas, seringas, frasco de álcool e frasco de hipoclorídrico;

Bioquímica/Biofísica: luvas, algodão, gazes, seringas, agulhas, lancetas, lamínulas, urina, papel branco, papel-toalha, sangue, ponteiras, lâminas de teste de afoiçamento, frasco de álcool e frasco de hipoclorídrico;

Imunologia/Genética: capilar, luvas, algodão, lancetas, sangue, urina, agulhas, seringas, fitas para urinálise, lamínulas, papel branco, papel-toalha, ponteiras, gazes, frasco de álcool e frasco de hipocloridrico;

Histologia de Resina: xilol, álcool (em várias diluições), corantes (hematoxilina e eosina), parafina, cera de abelha, algodão, papel branco, papel-toalha, papel-filtro, papel 
de embalagens, gaze, lamínulas, lâminas quebradas, bisturi, formol, luvas, restos de animais (peças e carcaças), agulhas, seringas, alfinete, papel-alumínio, ácido acético, óxido de mercúrio, frasco de álcool e frasco de hipocloridrico.

Todos foram coletados e separados manualmente.

\section{Análise, separação e quantificação dos resíduos coletados}

As análises dos resíduos de serviço de saúde dos laboratórios do campus Vassouras, da Universidade Severino Sombra foram realizadas por meio de observação dos resíduos contidos no interior do recipiente coletor, os quais foram identificados, separados e registrados conforme sua ocorrência, desde a sua geração até o seu encaminhamento ao setor responsável pelo descarte. Após esta etapa os resíduos foram quantificados e pesados, utilizando-se uma balança de precisão da marca Filizola e/ou medidos.

Em seguida, procedeu-se a caracterização dos resíduos com o objetivo de obter os dados de geração no local em estudo. Inicialmente, essa caracterização foi executada por meio de observação direta.

Durante a pesquisa verificou-se a reutilização de materiais antes considerados lixo nos setores administrativos e outras correlacionadas, a exemplo da reutilização de papel para rascunhos, frascos de álcool e hipocloridrico, vidros de medicação - depois de lavados e esterilizados - foram reutilizados, isto é, passaram pelo processo de reciclagem na própria área de estudo. Estes materiais que seriam desprezados, após a lavagem e esterilização foram de grande utilidade no manejo das aulas práticas nos laboratórios.

\section{Resultados}

Os resíduos de saúde gerados nos laboratórios de Saúde do campus Vassouras, da Universidade Severino Sombra foram estudados por um período de 107 (cento e sete) dias, no período supracitado os resíduos foram coletados, classificados, agrupados, e pesados e/ou medidos.

\section{Classificação dos Resíduos coletados nos laboratórios de saúde do campus Vassouras, da Universidade Severino Sombra conforme a RDC - ANVISA n. ${ }^{\circ} 306 / 04$ e Resolução CONAMA n. ${ }^{\circ}$ 358/05}

Para que de fato entenda-se toda a temática desta pesquisa, é necessário iniciar-se relacionando, classificando e agrupando os diferentes tipos de resíduos produzidos nas atividades realizadas dos laboratórios de saúde do campus Vassouras, da Universidade Severino Sombra em função de suas características e consequentes riscos que podem acarretar ao meio ambiente e à saúde considerando-se as normas estabelecidas pelos órgãos oficiais que os classificam em 5 (cinco) grupos distintos: a) Grupo A - Resíduos com risco biológico; b) Grupo B - Resíduos com risco químico; c) Grupo C - Rejeitos radioativos; d) Grupo D - Resíduos comuns e, e) Grupo E - Perfurocortantes como anteriormente conceituados. 


\section{Resíduos dos laboratórios da USS classificação A}

Barbantes com sangue, restos, peças e carcaças de animais, urina, fezes, capilares, fitas para urinálise, swab, placas descartáveis com meios de cultura, meios de cultura, cera de abelha, corantes e seringas.

\section{Resíduos dos laboratórios da USS classificação B}

Xilol, ácido acético; óxido de mercúrio, formol e fósforo.

\section{Resíduos dos laboratórios da USS classificação C}

Nos laboratórios de saúde do campus Vassouras, da Universidade Severino Sombra não são produzidos resíduos de classificação C.

\section{Resíduos dos laboratórios da USS classificação D}

Papel-toalha, luvas, papel-alumínio, algodão, álcool, papel pardo, papel-filtro, gaze, papel branco e alças descartáveis.

Resíduos dos laboratórios da USS classificação E

Lancetas, lâminas, lamínulas, bisturi, agulhas, lâminas de teste para aperfeiçoamento e lâminas quebradas.

\section{Distribuição dos Valores encontrados em relação à produção de resíduos de Serviços de Saúde}

Os resíduos gerados nos laboratórios de Saúde do campus Vassouras, da Universidade Severino Sombra foram estudados por um período de 107 (cento e sete) dias; estes, durante o período aludido, foram coletados, classificados, agrupados, e pesados e/ou medidos como mostram as tabelas em anexo.

Da coleta resultou o valor absoluto de 127.217,6g de resíduos de serviço de saúde os quais foram distribuídos conforme a figura 1.

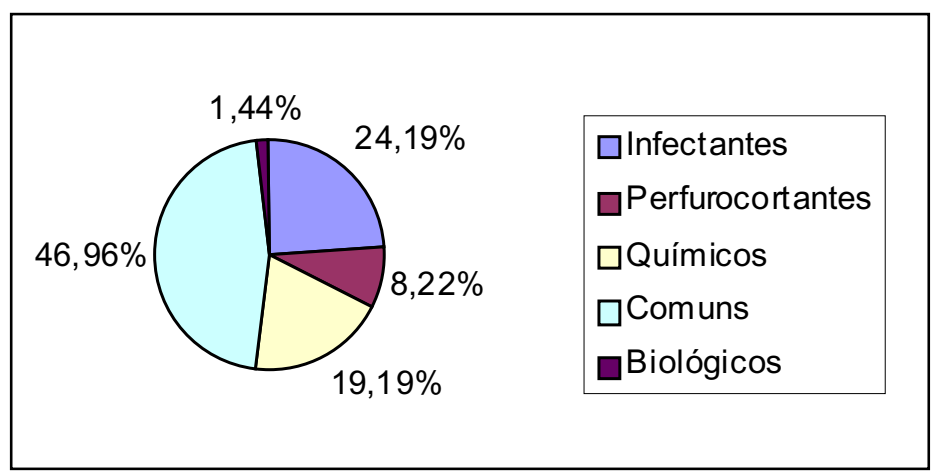

Figura 1. Distribuição dos Resíduos de Serviço de Saúde produzidos nos laboratórios do campus Vassouras, da Universidade Severino Sombra, por percentagem 
Foram organizados, segundo suas características, e quantificada a contribuição de cada grupo para o valor acima mencionado. O grupo dos resíduos infectantes contribuiu com 30.777,48g (Fig. 2), representando um percentual de 24,19\%, o grupo dos resíduos perfurocortantes somou $10.434 \mathrm{~g}$ (Fig. 3) ou 8,22\% do valor total de resíduos coletados, o grupo dos resíduos químicos forneceu 24.421,6g (Fig. 4), o que equivale a 19,19\% do valor total da coleta, 59.744,52 g foi o que se coletou em resíduos comuns (Fig. 5), o tipo mais produzido resultando em $46,96 \%$ do valor total e, por último e em menor valor, $1.840 \mathrm{~g}$ de resíduos biológicos (Fig. 6) ou 1,44\% do valor absoluto coletado.

De cada grupo específico observou-se a ocorrência nos laboratórios de Saúde do campus Vassouras, da Universidade Severino Sombra de cinco tipos de resíduos apurando-se os seguintes resultados:

Da coleta resultou o valor absoluto de 127.217,6g de resíduos de serviços de saúde os quais foram dispostos segundo suas características em 24,19\% de resíduos infectantes, $8,22 \%$ de resíduos perfurocortantes, $19,19 \%$ de resíduos químicos, 46,96\% de resíduos comuns e $1,44 \%$ de resíduos biológicos.

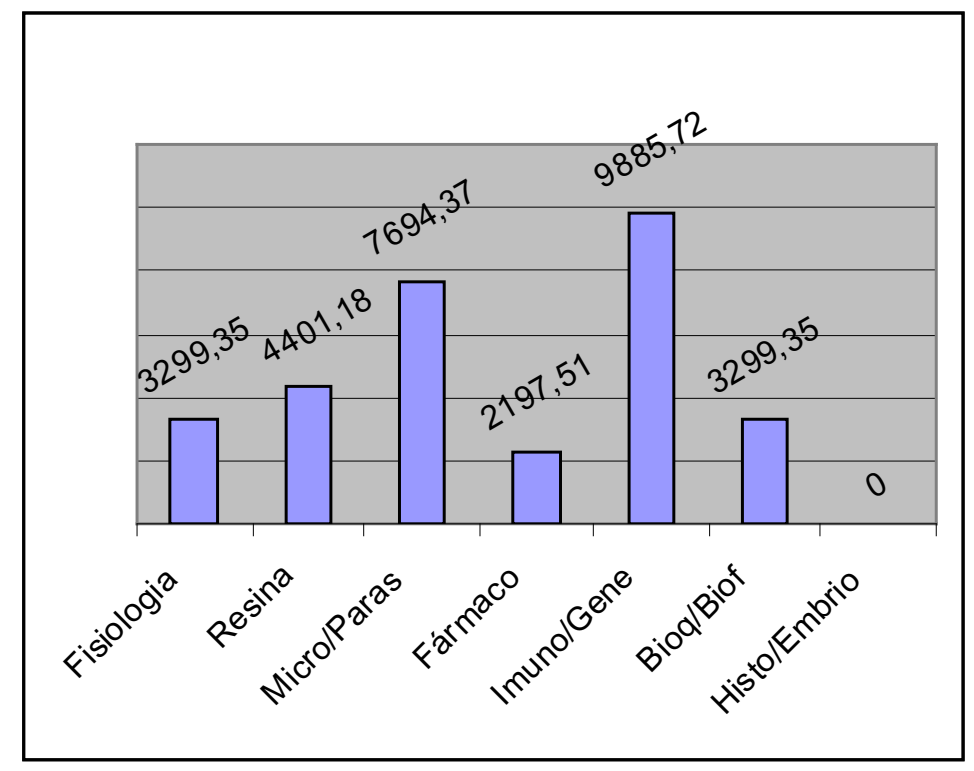

Figura 2. Distribuição dos resíduos infectantes nos laboratórios por grama

Por ocasião de ocorrência os resíduos infectantes ocupam a segunda colocação entre os tipos de resíduos produzidos nos laboratórios do campus Vassouras, da Universidade Severino Sombra. Durante o período de estudo foram gerados $30.777,48 \mathrm{~g}$ do citado resíduo sendo o Laboratório de Imunologia/Genética o maior produtor deste tipo de resíduo, contribuindo com $32,12 \%$ do valor coletado. 


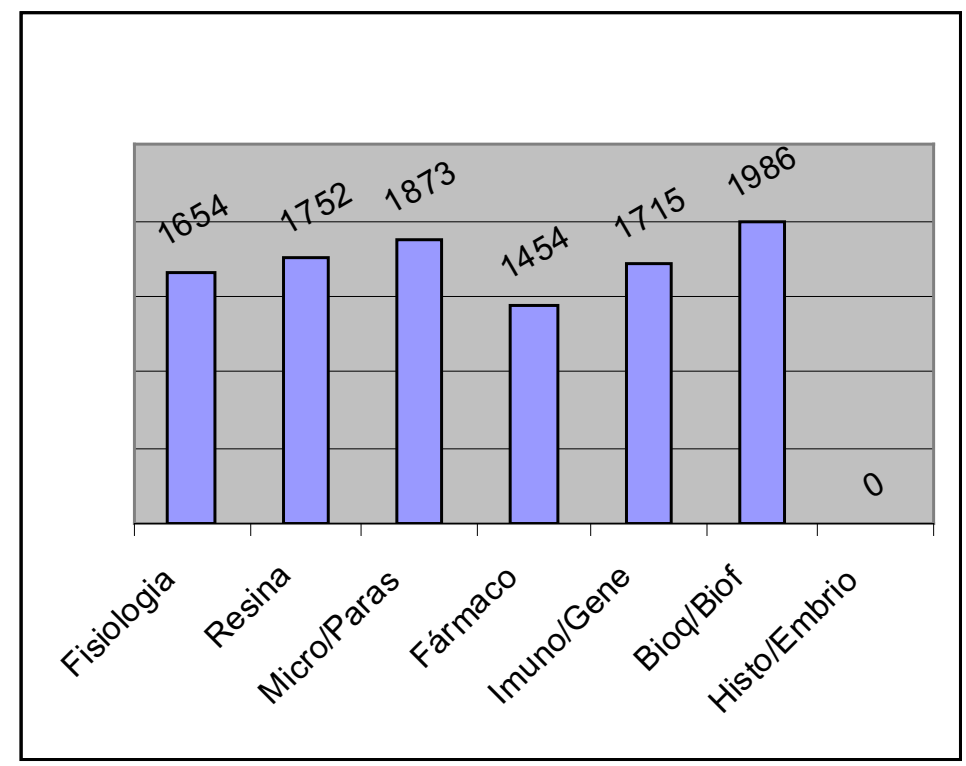

Figura 3. Distribuição dos resíduos perfurocortantes (Discarpack) nos laboratórios, por grama

A ocorrência de resíduos perfurocortantes foi de 10.434g durante o período de estudo, não muito significativa, levando-se em conta a sua relevância no desenvolvimento de pesquisas, exames e estudos, configurando o Laboratório de Bioquímica/Biofísica como o maior gerador de tal resíduo contribuindo com $19,03 \%$ de sua ocorrência.

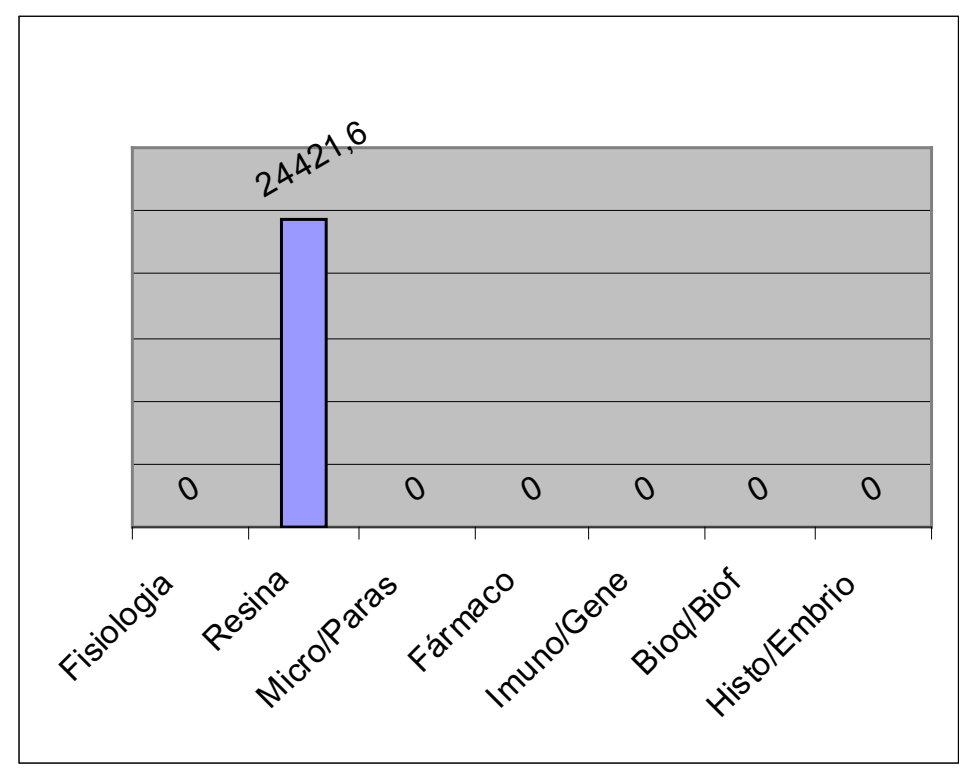

Figura 4. Distribuição dos resíduos químicos nos laboratórios por grama 
Gerenciamento de Resíduos dos Laboratórios da Área de Saúde do Campus da Universidade Severino Sombra, Vassouras - RJ

José Carlos do Nascimento - Rosana Canuto Gomes - Carlos Eduardo Cardoso - Luzia Teixeira de Azevedo Soares Semêdo

Durante o período de estudo foram gerados, somente pelo Laboratório de Resina, 31,700 mL de Resíduos Químicos, valor este que, considerada sua densidade equivale a $24,421,6 \mathrm{~kg}$.

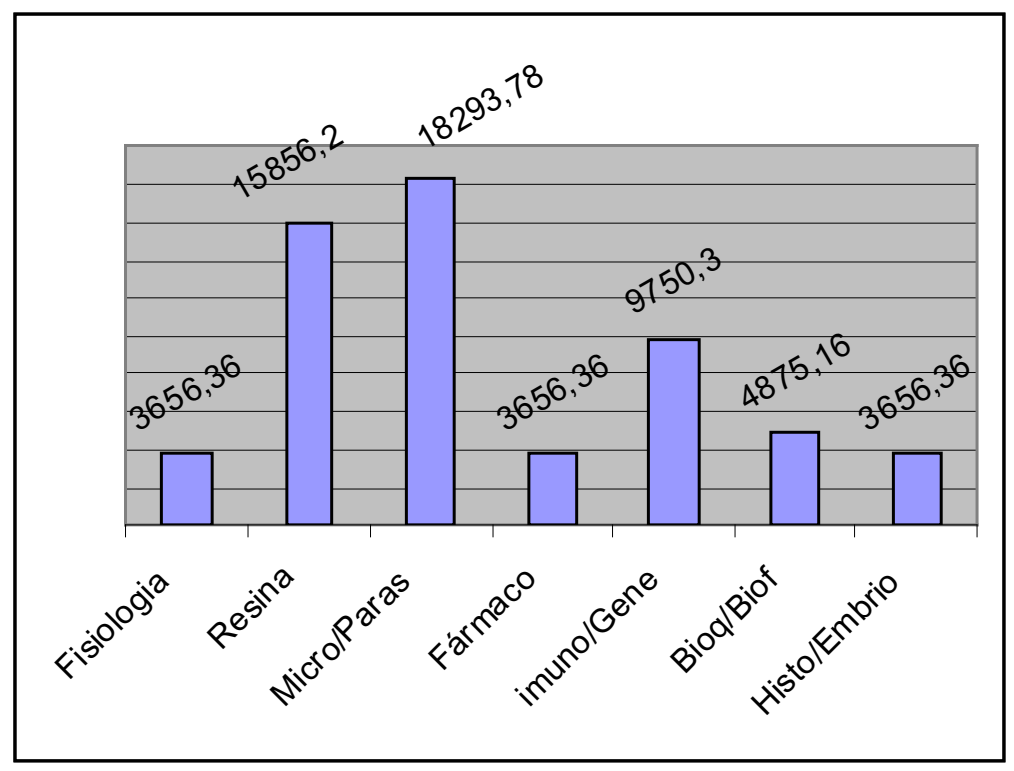

Figura 5. Distribuição dos resíduos comuns nos laboratórios por grama

Os resíduos comuns foram gerados por todos os laboratórios em estudo, sua produção total foi de 59.744,52g e o laboratório que mais contribui para este resultado foi o de Microbiologia/Parasitologia que detém 30,62\% desse valor.

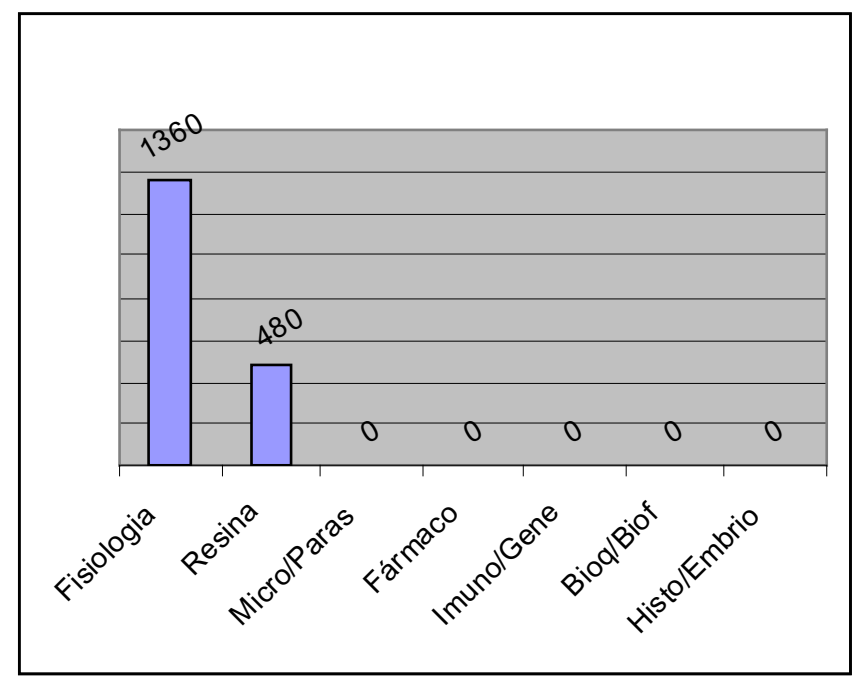

Figura 6. Distribuição dos resíduos biológicos nos laboratórios por grama 
Gerenciamento de Resíduos dos Laboratórios da Área de Saúde do Campus da Universidade Severino Sombra, Vassouras - RJ

José Carlos do Nascimento - Rosana Canuto Gomes - Carlos Eduardo Cardoso - Luzia Teixeira de Azevedo Soares Semêdo

Durante o estudo foram coletados $1.840 \mathrm{~g}$ de resíduos biológicos, os quais foram gerados nos Laboratórios de Fisiologia e Resina na proporção de 73,91\% e 26,09\% respectivamente.

\section{Discussão}

Os dados apresentados neste estudo foram coletados nos laboratórios de saúde do campus Vassouras, da Universidade Severino Sombra e correspondem às atividades realizadas em forma de pesquisas, exames e aprendizagens laboratoriais.

No decorrer das pesquisas constatou-se não haver nos arquivos da Universidade Severino Sombra outros estudos semelhantes ao presente, elaborados por alunos ou colaboradores da citada instituição de ensino, que pudesse lhe servir de comparativo e fundamento, todavia, trabalhos similares foram realizados em outras grandes universidades e hospitais e puderam alicerçar este estudo. Contudo, não servem de comparativo uma vez que, por localizarem-se em grandes centros vivenciam realidades diferentes.

Fez-se necessária, então, a comparação entre a frequência da ocorrência de cada tipo de resíduo e da produção dos laboratórios.

Observou-se que os resíduos comuns prevaleceram sobre os demais, com uma frequência de $46,96 \%$ contra $24,19 \%, 19,19 \%, 8,22 \%$ e $1,44 \%$ dos resíduos infectantes, químicos, perfurocortantes e biológicos respectivamente.

O laboratório de Resina configura-se como o maior produtor de resíduos com 46.910,98g, em seguida, porém com grande diferença de produção encontra-se o laboratório de Microbiologia/Parasitologia, com a produção de 27.861,15g, após o laboratório de Imunologia/Genética, com produção de 21.351,02g, o laboratório de Bioquímica/Biofísica, com produção de 10.160,51g, o laboratório de Fisiologia com produção de 9.969,71g, o laboratório de Farmacologia com 7.307,87g e por fim, o laboratório de Histologia com a produção de $3.656,36 \mathrm{~g}$ de resíduos. Convém salientar que os valores expressos na quantificação dos resíduos derivam da soma de cada tipo de resíduo produzido por laboratório.

Observou-se durante o período estudado que a produção de resíduos de serviços de saúde do laboratório de Histologia/Embriologia foi desproporcional à sua função, oferecendo resultados aquém do esperado; isso se deu pelo fato de que neste período não houve turma no curso de Medicina, ocorrência que trouxe danos ao estudo uma vez que implica em um resultado falso-negativo.

O estudo em questão não relata a existência de resíduos radioativos pelo simples fato de não se fazer uso de tal material nos laboratórios.

"Todos têm direito ao meio ambiente ecologicamente equilibrado, bem de uso comum do povo e essencial à qualidade de vida saudável, impondo-se ao Poder Público e à coletividade o dever de defendê-lo e preservá-lo para as presentes e futuras gerações" é o que preconiza o artigo 255 da Constituição da República Federativa do Brasil de 1988.

Manter o ambiente saudável não compete apenas ao poder público, o gerenciamento dos resíduos gerados pela população deve fundamentar-se em critérios sociais, isto é, na 
participação das pessoas geradoras de resíduos, para que todos possam definir localmente novas regras de convivência, novas normas e novos valores para a definição de seus padrões de produção e consumo, bem como a utilização de tecnologias mais apropriadas ao seu contexto.

A questão dos resíduos de serviços de saúde não pode ser analisada apenas no aspecto da transmissão de doenças infecciosas. Também está envolvida a questão da saúde do trabalhador e a preservação do meio ambiente, sendo essas questões preocupações inerentes a toda sociedade.

Esse trabalho mostrou a importância de se conhecer e quantificar os resíduos de serviços de saúde produzidos não apenas nos laboratórios de Saúde do campus Vassouras da Universidade Severino Sombra, mas em todos os estabelecimentos que produzem tais resíduos considerando-se que a segurança ocupacional é um direito de todo o trabalhador e está assegurada por lei e a responsabilidade de se manter o meio ambiente saudável é de todos.

Por meio deste estudo tornaram-se conhecidos os tipos de resíduos gerados nos laboratórios de saúde do campus Vassouras, da Universidade Severino Sombra, bem como a frequência com que são produzidos. Os resíduos gerados em atividades de pesquisa e análises de rotinas nestes laboratórios têm seu manejo e destinação controlados, observando-se as normas e regras de conduta que oferecem aos alunos e colaboradores da instituição de ensino maior segurança e à natureza menor risco de contaminação.

Conclui-se, portanto, que os procedimentos de manuseio e descarte dos citados resíduos pela instituição de ensino obedecem às determinações contidas na RDC n. ${ }^{\circ}$ 306/2004 da ANVISA e resolução CONAMA n. ${ }^{\circ}$ 358/2005.

Para que os resíduos de serviços de saúde possam ser eliminados de forma adequada é necessário educar os seus geradores, informando-os e conscientizando-os dos riscos causados pelo descarte inadequado, não só para a pessoa que faz o descarte, mas também para o profissional que recolhe tais resíduos e para a população que fica exposta, em um meio ambiente contaminado. É preciso, acima de tudo instituir políticas públicas, sérias, de controle e fiscalização que coíbam a irresponsabilidade de quem ainda não se conscientizou da importância de conservar o ambiente saudável. 


\section{Referências}

Agência Nacional de Vigilância Sanitária. (2006). Séries Temáticas Anvisa Tecnologias em Serviços de Saúde Volume 1; Brasília. Endereço: http://bvsms.saude.gov.br/bvs/ publicacoes/manual_gerenciamento_residuos.pdf Acesso em 15/06/2011.

Agência Nacional de Vigilância Sanitária. (2003). Resolução RDC 33, de 25 de fevereiro de 2003. Dispõe sobre o Regulamento Técnico para o gerenciamento de resíduos de serviços de saúde. Endereço: http://www.anvisa.gov.br/legis/resol/2003/rdc/33_03rdc. htm Acesso em: 19/06/2011.

Agência Nacional de Vigilância Sanitária. (2010). Manejo e descarte de resíduos laboratoriais. Endereço: www.anvisa.gov.br/reblas/procedimentos/manejo.pdef Acesso em: 19/6/2011.

Brasil. Constituição da República Federativa do Brasil: artigo 225. Brasília, 1988. Endereço:http://www.fundabrinq.org.br/_Abrinq/documents/publicacoes/Con1988br. pdf Acesso em: 19/06/2011.

Brasil, Ministério da Saúde. (2004) Agencia Nacional de Vigilância Sanitária. Resolução da Diretoria Colegiada - RDC No 306, de 07 de dezembro de 2004. Dispõe sobre o Regulamento Técnico para o gerenciamento de resíduos de serviços de saúde. Endereço: http://www.anvisa.gov.br/servicosaude/avalia/legis.htm\#37 Acesso em $19 / 06 / 2011$

Brasil, Ministério da Saúde. (2002). Secretaria de Gestão de Investimentos em Saúde. Guia do Estudante e Caderno de Atividades. Endereço: http://bvsms.saude.gov.br/bvs/ publicacoes/caderno_atividades_curso.pdf Brasília. Acesso em 09/07/2011.

Brasil, Ministério da Saúde. (2002). Secretaria de Gestão de Investimentos em Saúde. Saúde Ambiental e Gestão de Resíduos de Serviços de Saúde. Endereço: http://bvsms. saude.gov.br Acesso em 11/06/2011.

Garcia, L. P; Ramos, B. G. Z. (2004). Gerenciamento dos resíduos de serviços de saúde: uma questão de biossegurança. Caderno de Saúde Pública, Rio de Janeiro; mai/jun, v. 20, n. 3

Instituto Brasileiro de Geografia e Estatística. (2010). Pesquisa nacional de saneamento básico: limpeza urbana e coleta de lixo. Endereço: http:/www.ibge.gov.br/home/ estatistica/populacao/condiçãodevida/pnsb/lixo_coletado/defaultlixo.shtm Acesso em:19/06/2010

Jusbrasil. (2011) Disponível em: http://www.jusbrasil.com.br/diarios/24097488/dospexecutivo-caderno-1-11-01-2011-pg-38. Acesso em: 06 DEZ

Monteiro, J. H. P. (2001). Manual de Gerenciamento Integrado de resíduos sólidos. Coordenação técnica Victor Zular Zveibil. (Instituto Brasileiro de Administração Municipal: IBAM). Rio de Janeiro: 200p.

Organização Pan-Americana da Saúde. (1997). Guia para o manejo interno de resíduos sólidos em estabelecimentos de saúde. Centro Pan-Americano de Engenharia Sanitária e Ciências do Ambiente. Brasília: p. 60.

Ribeiro Filho, V.O. (2000). Gerenciamento de resíduos de serviços de saúde: infecção hospitalar e suas interfaces na área da saúde. São Paulo: Atheneu, p.1157. 
Secretaria Estadual de Saúde de Goiás. (2004). Manual de gerenciamento de resíduos de serviços de saúde. Goiás. Endereço: http://www.visa.goias.gov.br/arquivos/manual_ PGRSS.pdf . Acesso em 24/7/2011.

Silva, R. F. S. da; Soares, M. L. (2004). Gestão dos resíduos sólidos de serviços de saúde com responsabilidade social. Universidade Paranaense - UNIPAR. Cascavel/PR. Endereço: http://www.bvsde.paho.org/bvsacd/cd51/silva.pdf Acesso em 14/7/2011.

Takada, A. C. S. (2003). O plano de gerenciamento de resíduos de serviços de saúde e $o$ direito do trabalhador. 35f. Monografia (Especialização) Escola Nacional de Saúde Pública. Brasília. 